\title{
Cultural adaptations of CBT: a summary and discussion of the Special Issue on Cultural Adaptation of CBT
}

\author{
Farooq Naeem \\ University of Toronto and Centre for Addiction and Mental Health, Toronto, Canada \\ Corresponding author. Email: farooqnaeem@yahoo.com
}

(Received 09 June 2019; revised 15 July 2019; accepted 22 July 2019)

\begin{abstract}
Cognitive behavioural therapy (CBT) in its current form might not be acceptable to service users from a variety of backgrounds. Therefore, it makes sense to adapt CBT when working with diverse populations. Contributors to this special issue of the Cognitive Behaviour Therapist have tackled the issues around the cultural adaptation of CBT from various perspectives, using a variety of methods, and have addressed topics ranging from cultural adaptation to improving access to CBT. Here, I briefly summarize and discuss the papers in this special issue. I start with a systematic review of CBT for social anxiety across cultures. Seven articles cover aspects of adaptation of therapies for people from different backgrounds. Three papers discuss the issues of gender and sexuality when using CBT, while another three papers focus on refugees, asylum seekers and the homeless, and two papers describe the application of CBT with religious populations. Finally, there are seven papers on issues related to service delivery, practice and training and supervision when working with a diverse population. Collectively, papers in this special issue provide us with sufficient evidence that cultural considerations play a vital role when using CBT, offer practical suggestions for improving cultural competence and most importantly, can catalyse future research. However, the full potential of culturally adapted interventions will not be realized until and unless access to CBT is improved. Therefore, there is a need to build robust evidence to convince funders, policy makers and service managers.
\end{abstract}

Keywords: cognitive behavioural therapy; cognitive therapy; cross-cultural; cultural adaptation; trans-cultural

\section{Introduction}

The UNESCO (United Nations Educational, Scientific and Cultural Organization) universal declaration on cultural diversity defines culture as 'the set of distinctive spiritual, material, intellectual and emotional features of society or a social group, and that it encompasses, in addition to art and literature, lifestyles, ways of living together, value systems, traditions and beliefs' (UNESCO, 2001). The term sub-culture is used to refer to minority cultures within a broader dominant culture. This declaration asserts that cultural pluralism pre-supposes respect for human rights. Most importantly, this definition does not limit culture to race, religion or nationality, thus recognizing cultural aspects of groups based on gender, gender preferences, age and disabilities. These values underpin the principle of cultural adaptation of evidence-based psychosocial interventions for people from diverse cultural and sub-cultural backgrounds.

Cognitive behavioural therapy (CBT), like most modern psychotherapies, is underpinned by the European-American values (Hays and Iwamasa, 2006; Naeem et al., 2019; Stone et al., 2018). CBT involves exploration and attempts to modify core beliefs. Core beliefs, underlying assumptions and even the content of automatic thoughts vary across cultures (Sahin and Sahin, 1992; 
Tam et al., 2007). Cultural and sub-cultural background also influence beliefs about wellbeing, causes of illness and its cure, help-seeking behaviours, healing systems and even the healers (Altweck et al., 2015; Bhugra, 2006; Bhugra and Bhui, 1998; Hagmayer and Engelmann, 2014).

CBT research until recently has primarily focused on white, middle-class, well-educated service users, who are of European-American identities (Suinn, 2003). It is not common practice to report participant's cultural or religious background in CBT research. Even when the participant's background is reported, a broader term such as White, Asian or Black is used, ignoring variations among these groups. Similarly, researchers do not record information concerning participants' sexual orientation (Bowen and Boehmer, 2007).

Culturally adapting CBT is the only way access to this evidence-based therapy can be improved for marginalized communities in Europe and North America and for the local population outside of these regions where more than $80 \%$ of the world population lives. It is heartening to see this field grow over the past decade to the extent that it found its place in a special edition of a highly prestigious journal. This special edition, therefore, is a welcome addition to a fast-growing area in CBT research and practice: 'the cultural adaptation of CBT'.

\section{Summary and discussion}

This special issue addresses a variety of problems, populations and psychotherapies. I have tried to divide these articles according to the broader themes, although most articles will fit in more than one thematic area. There is (a) one systematic review of CBT for social anxiety among the culturally diverse population (Jankowska, 2019). There are (b) seven articles covering different aspects of adaptation of therapies for diverse populations which include: culturally adapted family intervention using case studies (Berry et al., 2018), a discussion of maladaptive schema and schema therapy in the context of Greek culture (Kolonia et al., 2019), use of a transdiagnostic intervention in low resource countries (Murray et al., 2019), application of acceptance and commitment therapy (ACT) with a Turkish population in London (Perry et al., 2019), a framework to culturally adapt CBT (Rathod et al., 2019), a case report of family-based CBT for obsessive compulsive disorder (OCD) from Saudi Arabia (Alatiq and Alrshoud, 2018) and a paper discussing CBT in military culture (Zwiebach et al., 2019). Three papers (c) address the issues of gender and sexuality. One paper discusses the application of dialectical behaviour therapy (DBT) with LGBTQ service users (Skerven et al., 2019), another describes a case series of vaginismus therapy in Tunisia (Zgueb et al., 2019), while the third paper reports use of behaviour therapy when working with gender and sexual minorities in the context of Islamic culture (Langroudi and Skinta, 2019). Three papers (d) focus on refugees, asylum seekers and the homeless. One paper describes a practice protocol for dissociative symptoms (Chessell et al., 2019), another describes the use of CBT with asylum seekers (King and Said, 2019), and the third paper describes CBT with Mexican homeless girls (Castaños-Cervantes, 2019). Two papers (e) focus on CBT for two religious groups, i.e. Orthodox Jews and Muslims (Kada, 2019; Mir et al., 2019). Finally, this special issue publishes seven articles (f) on issues related to service delivery, practice, training and supervision when working with a diverse population. The first article discusses the need for service change to improve access to culturally adapted therapy (Beck and Naz, 2019). The second article describes an evaluation of the transition from the Black, Asian and minority ethnic (BME) community mental health worker to the IAPT low-intensity psychological wellbeing practitioner (Hakim et al., 2019). The third article discusses issues of race, cthnicity and culture in CBT to support therapists and service managers to deliver culturally competent therapy (Naz et al., 2019). The fourth article emphasizes understanding a client's experience of racism as part of the assessment, formulation and treatment (Beck, 2019). The fifth study reports findings from a qualitative study of therapists' experience of CBT training in Tanzania (Stone and Warren, 2011). Finally, two papers describe the importance of self-reflection, self-practice and supervision (Brooks, 2019) and therapist self-disclosure (Phiri et al., 2019). 
I will now briefly consider each of the papers in this special issue of the Cognitive Behaviour Therapist, providing a short summary of each paper, followed by a discussion, including suggestions on further enhancing our understanding of cultural issue related to CBT and on further promoting CBT across cultures and the subcultures.

\section{(a) A systematic review of CBT for social anxiety within a culturally diverse population}

Cultural modifications of cognitive behavioural treatment of social anxiety among culturally diverse service users: a systematic literature review (Jankowska, 2019)

This systematic review reports case studies, as there were no randomized controlled trials (RCTs) in this area. The review focuses on seven case studies of cultural adaptations of CBT for social anxiety disorder (SAD) for a culturally diverse population published separately. The treatment outcomes were generally promising in all cases, reporting a significant decrease of SAD symptoms, which were maintained over time. The success of therapy was attributed to the culturally specific modifications. However, the authors point out that there was little discussion or consideration given to other, non-culture-related factors that could potentially contribute to the success of therapy. Case studies in this review were reported from the USA and Japan. The authors concluded that CBT can be an acceptable and effective treatment for culturally diverse SAD sufferers with 'modest' modifications, and that applying them increases the treatment compliance and its outcomes, although they issue caution based on the quality of reporting and multiple methodological issues.

The assertion that the expression of social anxiety is influenced by social and cultural factors (Hofmann et al., 2010) has common sense appeal. While lower prevalence rates of SAD are reported from some non-Western cultures (Hofmann et al., 2010), these might be due to individuals seeking help from practitioners of traditional, complementary and alternative medicine (Gureje et al., 2015). Reviewers report that therapists claimed that they practised cultural awareness and were open to discuss culture and were attentive to cultural norms as well as culture-specific expressions of SAD and the level of acculturation. However, therapy was not adapted using a systematic approach. Some examples of cultural sensitivity included: need to be aware of service user's culture, language barriers and translations, level of acculturation, socio-cultural constructs, therapeutic relationship and style of therapy, which are in line with the existing literature (Hays and Iwamasa, 2006; Hwang et al., 2015; Naeem et al., 2019; Organista and Muñoz, 1996; Ward and Brown, 2015). As the review included only a small number of case studies, it will be too early to draw any conclusions. However, findings from this review certainly draw attention to the need for more research in this area.

\section{(b) Cultural adaptation of therapies for a diverse population}

\section{Culturally adapted Family Intervention (CaFI): case examples from therapists' perspectives (Berry et al., 2018)}

These authors pioneered cultural adaptation of a CBT-based family intervention for psychosis for African-Caribbean people in England, and found it to be feasible and acceptable (Edge et al., $2018 \mathrm{a}, \mathrm{b})$. This paper reports on the process of culturally adapted family intervention from a therapist's perspective. The authors report three cases to describe the therapy process, insights learned by therapists and compared those with the original model they developed. Therapists focused on cultural factors during assessment and engagement, shared learning, communication, coping skills and endings. In particular, it was possible to engage service users in family intervention for psychosis with and without biological family members.

People of African-Caribbean origin in the UK have a higher incidence of schizophrenia (Fearon et al., 2006), and are less likely to receive psychological therapies (Morgan et al., 2006). A qualitative study from Montreal to explore the reasons for the under-use of conventional 
mental health services by people of Caribbean origin reported that tendency of physicians to prescribe pills is a significant barrier. Psychological interventions, therefore, can play a vital role in engaging these clients. Family intervention reduces hospital admission, encourage compliance with medication, improves general social impairment and the levels of expressed emotion within the family (Pharoah et al., 2010), and therefore is recommended by NICE (NICE, 2014). Family interventions might be more appealing to people from collectivistic cultural backgrounds, and therefore the adaptation of family intervention for this group might improve access, engagement and thus outcomes. These findings confirm some of the findings from cultural adaptation of individual CBT for psychosis (Li et al., 2017; Naeem et al., 2014; Naeem et al., 2015b; Rathod et al., 2010; Rathod et al., 2013), in particular the role played by trauma, coercive treatment and racism (Rathod et al., 2010). There is, however, a need to confirm the effectiveness of culturally adapted family interventions through fully powered RCTs. I also suggest that authors should consider replication of this model in other countries, especially non-Western countries.

Schema Therapy and the use of Politeness Plural in Greek-speaking populations: a need for cultural adaptation or a quest for early maladaptive schemas/modes? (Kolonia et al., 2019)

This paper examines the Greek cultural, linguistic schema of Politeness Plural in the application of a Schema Therapy mode model. The authors argue that holding on to the 'Politeness Plural linguistic schema' may reinforce emotional distancing and might compromise schema healing. Schema Therapy emphasizes the need for creating a warm therapist-client relationship as a pre-requisite for schema healing. The authors advise that a schema therapist needs to remain inquisitive of potential maladaptive or/and internalized dysfunctional coping mechanisms of inter-relating that are masked by the use of the Politeness Plural linguistic schema. The authors suggest that any attempt at holding on to the Politeness Plural cultural, linguistic schema in the Greek-speaking culture employed by either the therapist or the client reinforces emotional distancing and prevents the therapy from working through those maladaptive coping and internalized dysfunctional mechanisms of self that perpetuate schemas on both.

Both verbal and non-verbal language plays a vital role in psychotherapeutic encounters. It has been proposed that our knowledge of language use can be used as a source of 'technologies' for investigating the process of psychotherapy (Russell, 1989). This interesting article provides food for thought for every therapist. The ideas proposed by the authors should also appeal to therapists from non-Western cultures. The $\mathrm{t}-\mathrm{v}$ (tu-vos) distinctions are common around the globe and expressed in a variety of forms. In some non-Western cultures, these expressions are accompanied by a set of gestures, for example, lowering of eyes or head (Cultural Atlas, 2019). While egalitarian societies are subtle in acceptance of authority figures, in other societies showing respect for authority is a cultural norm and therefore hard to negotiate. A collaborative approach might not be acceptable across cultures. I agree with the assertion that these ideas need to be tested through qualitative and quantitative research.

\section{Under the hood: lay counsellor element use in a modular multi-problem transdiagnostic intervention in lower resource countries (Murray et al., 2019)}

Murray and colleagues (2019) present data from two previously conducted RCTs (Bolton et al., 2014; Weiss et al., 2015) in which they tested a modular, multi-problem, transdiagnostic manual using the common elements treatment approach (CETA). Therapy was delivered by lay counsellors in Iraq and Thailand to treat trauma victims. The authors examined the fidelity and flexibility of treatment elements. They gathered information at multiple points using a variety of methods. The lay counsellors, under supervision, demonstrated high levels of fidelity to the intervention. The authors concluded that the lay counsellors delivered the intervention flexibly and were able to learn the decision-making processes of the therapy manual. 
The authors suggest more process research in the use of transdiagnostic therapy manuals in low- and middle-income countries.

Transdiagnostic mental health interventions have been tested in Uganda, Iraq, Thailand, Pakistan and India (Bolton et al., 2014; Bonilla-Escobar et al., 2018; Patel et al., 2010; Rahman et al., 2016; Weiss et al., 2015). This approach is supported by the World Health Organization (WHO) as depicted in mhGAP (WHO, 2015), which promotes scaling up of evidence-based interventions and emphasizes the role of lay counsellors in delivering these interventions directly to the community members. These are commendable efforts. However, it is yet to be determined how sustainable these therapies are in the long term. So far, the uptake of these interventions into health systems has been low (Naeem et al., 2016a). The mental health systems in low- and middle-income countries (LAMICs) are under-resourced, limited to big cities and fragmented (Rathod et al., 2017). Not all the LAMICs are the same, with wide variations in terms of the level of education, resources and availability of trained therapists. The creation of a new workforce requiring additional funding might pose a barrier in uptake into the systems with low resources, or might not be necessary. There is a need to consider ways to deliver these interventions without putting extra demands on health systems while taking into consideration the available resource. Engaging local mental health professionals can play a vital role in this regard to understand the ground realities, rather than taking a public health approach. While the authors mention elements of cultural adaptation of the manual, no systematic attempts were made to adapt the manual culturally. This issue can be addressed in future research.

\section{Exploring the cultural flexibility of the ACT model as an effective therapeutic group intervention for} Turkish speaking communities in East London (Perry et al., 2019)

Acceptance and commitment therapy (ACT) is a trans-diagnostic intervention that has been tried both in the West and outside the West. This paper reports the cultural adaptation of ACT for the Turkish-speaking community in England. This study reports the results of post-intervention effects of a culturally adapted ACT group. The group intervention reduced depression, anxiety and emotional distress. Qualitative responses indicated that the culturally adapted ACT was feasible and acceptable. The authors describe the process of cultural adaptation in some detail, e.g. use of popular teachings and poems of Rumi, culturally familiar, non-technical language and video material from popular Turkish media and culturally syntonic translation of the therapy material.

Several attempts have been made at adapting third wave therapies (Cheng and Merrick, 2017; Fuchs et al., 2013; Mercado and Hinojosa, 2017; Ramaiya et al., 2017). Kenneth Fung has reported high levels of acceptance of ACT while working with the Cambodian community in Toronto (Fung, 2015). The notion that mindfulness-based therapies might be readily acceptable to people from a non-Western background has a common sense appeal. However, mindfulness might not be acceptable to everyone from outside the West due to religious or cultural reasons. Mindfulness-based approaches as practised in the West have also been criticized as either lacking the philosophical, theoretical or theological underpinning (Kirmayer, 2015) or even being a tool misused by the capitalist West (Illing, 2019). Sufism, an equivalent of mindfulness in Islam, might be more acceptable for Muslim clients and is worth exploring in this context. Nevertheless, third wave therapies should be culturally adapted and tested. We hope for further research to test this adapted therapy against standard ACT, using improved design and adequately powered RCTs that focus on specific problems. 
opinions and experiences to develop guidelines that can be used to adapt CBT for clients from a non-Western background culturally. They describe the 'triple-A principle' which describes foci of adaptation. These include 'awareness' of the service users' culture, consideration of cultural issues during the 'assessment and engagement phase' and areas in therapy that need 'adjustment' for therapy to be effective.

There are multiple arguments in favour of adapting CBT for people from a diverse background (Sue et al., 2009). While frameworks in the past were based on therapists' personal experience, these authors have described a systematic approach to culturally adapt CBT that is based on evidence and has been tested through RCTs. This paper, therefore, is a welcome addition to the existing literature in the area. The authors have expanded on their work over a decade in developing a framework for cultural adaptation of CBT that can be replicated (Naeem et al., 2015a; Naeem et al., 2016a,b; Naeem et al., 2019; Rathod et al., 2010). The major limitation of this framework is that it focuses on CBT and might not be generalizable to other therapies.

\section{Family-based cognitive behavioural therapy for obsessive-compulsive disorder with family accommodation: a case report from Saudi Arabia (Alatiq and Alrshoud, 2018)}

This case report describes the application of CBT in dealing with family accommodation (defined as 'how relatives, in particular parents, may assist in compulsive rituals, provide reassurance or modify their routines to alleviate or avoid the distress experienced by the obsessive-compulsive child'). The authors describe the mother of a 14-year-old female patient who carried out almost all the compulsive behaviours and rituals for her child. Family-based cognitive behavioural therapy was offered over 4 months with a successful treatment outcome. Exposure and response prevention was used to help the client. The authors concluded that if applied thoughtfully, CBT can be used for patients in Saudi Arabia.

Only limited literature is available on CBT with Arab clients (Kayrouz et al., 2018). These authors suggest that young children cannot be treated without considering attachment patterns, the broader family system and cultural variables. However, they claim that in this case, the cultural context and the broader family system were not the primary factors in the development and maintenance of the problem. It is, however, envisaged that therapists shared the same cultural values as the client, might be mindful of these norms, and possibly delivered therapy in Arabic - some vital aspects of cultural adaptation. They suggest that educating service users on CBT plays a vital role in cultures where people, in general, are not aware of CBT. The finding that behavioural techniques need few adjustments and are almost culture free has been previously reported (Naeem et al., 2010).

Military cultural competence in the context of cognitive behavioural therapy (Zwiebach et al., 2019) These authors start by highlighting the need to recognize a 'military culture' in therapeutic encounters. They suggest that CBT compliments many aspects of military culture, for example agenda setting (emphasis on the daily structure), explicit goals for treatment (focus on mission completion) and focus on skill training (development of strengths). They also discuss the sub-cultures within the army, based on religion, race or gender, etc. The authors emphasize some of the salient features of military culture: the organizational structure of the military and its branches, a timeline of major wars and operations, the ranking hierarchy, and its language that should be considered in adapting therapy for this group. Finally, the authors list available resources in training in military culture for therapists.

Many authors have pointed to the uniqueness of military culture as being different from civilian culture, based on routines, structures, hierarchies and the dress codes, among many other attributes (Hall, 2011; Reger et al., 2008; Soeters et al., 2006). Military personnel share a common bond, feeling of unity and a sense of purpose and direction. Understanding military 
culture becomes even more critical for civilian mental health professionals who are providing help to military personnel or veterans. Very high rates of post-traumatic stress disorder (PTSD), depression, anxiety and psychological distress have been reported among army personnel and veterans (Hoge et al., 2004; Statistics Canada, 2014; Stevelink et al., 2015). It is therefore surprising that only limited literature is available on the adaptation of psychotherapy with military personnel (Miller, 2010; Spoont et al., 2003). There is a need to adapt CBT for this group using a systematic approach.

\section{(c) Gender and sexuality}

Applying dialectical behaviour therapy to structural and internalized stigma with LGBTQ+ service users (Skerven et al., 2019)

Skerven et al. (2019) report adaptation of DBT to address the needs of service users with diverse gender identities and sexual orientations who have experienced sexual stigma. For sexual minorities, minority stress has been implicated as an increased risk of emotional and mental health disorders. This paper describes combining DBT with a sexual stigma model (Herek et al., 2009) for LGBTQ+ service users receiving therapy for borderline personality disorders. Authors believe combining these two paradigms can help LGBTQ+ service users in effectively interacting with this population. The authors provide case examples. They suggest more empirical research in this field.

DBT combined techniques from behaviour therapy and Zen Buddhism (Reddy and Vijay, 2017) and was developed to help suicidal behaviours among borderline personality disorder service users (Linehan et al., 1991). There is evidence to suggest that DBT is an effective treatment (Méndez-Bustos et al., 2019; Panos et al., 2014). A Cochrane Review reported that DBT reduces the frequency of repetition of self-harm, although no differences were observed in the proportion of patients repeating self-harm or other outcomes such as suicidal ideation and depression (Hawton et al., 2016). Stigma and discrimination based on sexual orientation or gender identity have a severe impact on the mental health of LGBTQ+ people (Meyer, 2003). Despite very high rates of mental health problems and suicidal behaviours, the LGBTQ+ community faces numerous barriers in accessing mental healthcare (Veltman and Chaimowitz, 2014). This paper highlights a gap and provides the way forward in working with a highly stigmatized group.

Cultural aspects of vaginismus therapy: a case series of Arab-Muslim patients (Zgueb et al., 2019)

This paper describes the use of CBT with four patients with vaginismus in Tunisia. All these patients had a strict religious upbringing and had dysfunctional beliefs underpinned by their cultural and religious values. The authors describe culturally adapted techniques they used to make therapy compatible with the local cultural context. They argue that family systems, religion and local cultural beliefs should all be taken into consideration when providing culturally adapted CBT.

In addition to describing the culturally adapted CBT techniques, the authors highlight the issues of gender discrimination and female sexuality in Muslim countries (Gouda and Potrafke, 2016). Culture, religion and spirituality influence the belief systems of people, including beliefs about illness, its causes and treatment (Cinnirella and Loewenthal, 1999; Ismail et al., 2005; Razali et al., 1996). The authors describe dealing with religious and cultural beliefs, and the role played by the family, engaging family members in therapy, dealing with shame and guilt, and local practices, such as magic rituals. They also highlight the culturally sensitive practice of involving faith or religious healers in therapy (Kada, 2019; Mir et al., 2019; Naeem et al., 2015a).

\section{Working with gender and sexual minorities in the context of Islamic culture: a queer Muslim behavioural approach (Langroudi and Skinta, 2019)}

The number of Muslims migrating to Europe and North America has increased over the last decade. Gender and sexual minorities (GSM) are over-represented in the migrating population. This 
population is at an increased risk of emotional and mental health problems. The authors discuss the impact of minority stress, shame and migration stress in this group. They also discuss the integration of ACT and compassion-focused therapy (CFT) in helping this population. The authors suggest that ACT and CFT may provide a practical framework for a culturally adapted therapy that targets the needs of those experiencing intersectional LGBTQ+ and Muslim identities.

The attitudes towards LGBTQ+ in Muslim countries have been influenced by religion and Islamic jurisprudence, as well their social, political and cultural history. Same-sex relationships were generally tolerated in pre-modern Islamic societies. Homoerotic themes were prevalent in poetry and other literary genres written in major languages of the Muslim world from the eighth century into the modern era (El-Rouayheb, 2005). However, prejudice towards this community worsened in the Islamic world, possibly due to the European laws during the colonial period and the rise of Islamist fundamentalism in the 1980s (The Economist, 2018). These authors have touched on a highly sensitive issue in a very skilful, diligent and empathic manner. They have presented a succinct rationale for the use of ACT and CFT to help Muslim GSM who might migrate to the West to avoid harsh treatment, but might feel trapped due to their experience of racism and anti-Islamic feelings in their host societies. Their distress is compounded by views of their family at home and members of their community in their host country. Additionally, they have to adjust to the differences in the expression of love, lust and romance. As homosexuality is considered a sin in Islam, it might be worth exploring the link between the concept of sin and associated shame in this context. Furthermore, individuals might vary in their level of acculturation and religiosity, and this should be taken into consideration (Joseph and DiDuca, 2007). Authors are encouraged to further this work by developing a manualized intervention that can be tested through experimental research.

\section{(d) Refugees, asylum seekers and the homeless}

A protocol for managing dissociative symptoms in refugee populations (Chessell et al., 2019)

When working cross-culturally, many consider a 'universalist' approach to help focus on the similarities across cultures, rather than emphasizing differences (Beck, 2016). This article describes a clinical protocol for supporting those presenting with PTSD and severe dissociative symptoms, particularly dissociative flashbacks, based on a cross-culturally applicable model. The protocol is discussed from the perspective of working with a refugee and asylum seeker population. However, it might be applicable across cultures. The protocol was developed in a specialist NHS (National Health Service, England) programme for migrants with PTSD. The dissociative responses are explained using the ' 6 Fs' cascade. Currently, a quantitative evaluation is underway.

This brief manualized intervention can be delivered in four sessions and might be applicable across cultures. As language can be a barrier, authors provide some guidance on training interpreters. Both 'the cultural adaptation of CBT' that focuses on differences across cultures and a 'universalist approach focusing on similarities across cultures' merit further investigation. We are already discovering that behavioural approaches might need few changes in their application across cultures (Alatiq and Alrshoud, 2018). The suggestion that individual variations and environmental factors shape stress response might apply to groups of individuals (Ellis et al., 2006). It must also be emphasized that some elements of adaptation are universal, such as adapting to the language needs of the service users. There is a need for more research in culture free aspects of CBT and to test these ideas across cultures.

\section{Working with unaccompanied asylum-seeking young people: cultural considerations and acceptability of a cognitive behavioural group approach (King and Said, 2019)}

This paper describes the development of a culturally adapted intervention and outlines a psychological skills group for unaccompanied asylum-seeking children (UASC). The authors 
also report feasibility, acceptability and preliminary effectiveness of the intervention. The principles of CBT underpinned the intervention, with elements of DBT, CFT and ACT. As the UASCs have typically experienced multiple losses, traumatic experiences, significant disruption and psychosocial stressors, a trauma focus approach was used.

The prevalence rates of mental health difficulties among UASC are understandably higher than among children seeking asylum with their families, or children who are not from refugee or asylum-seeking backgrounds. This intervention was planned around three key themes: physical health needs, emotional wellbeing, and resilience-building. The authors considered adaptations at numerous levels. In terms of the mode of delivery, a group approach was considered more suitable to provide peer support and normalization for the UASC. Other notable examples of adaptation include: engagement (games, demonstrations, metaphors), use of interpreters to address the language needs of the group, and considering physical health needs at the start of the intervention. These adaptations are in line with our current knowledge of cultural adaptations described by other authors in this special issue. The next step should be a large scale evaluation of the manualized form of this intervention.

\section{Brief CBT group therapy for Mexican homeless girls (Castaños-Cervantes, 2019)}

Susana Castaños-Cervantes (Castaños-Cervantes, 2019) describes the preliminary efficacy of a brief cognitive behavioural group therapy group intervention tailored to Mexican homeless girls. The intervention reduced anxiety, depression and emotional dysregulation, and improved assertiveness. These effects persisted on follow-up. The adaptations were made at structural and didactic levels. Structural adaptations included changes in the language. Didactic adaptations focused on improving engagement and included the use of audiovisual material. Developmental considerations included focusing on concrete concepts, using simplified language, vocabulary, and age-appropriate activities.

The 'subculture of homelessness' has been described as the culture of individuals who are homeless and share similar beliefs, values, norms, behaviours, social structures, and a common economic situation, all in response to a comparable living environment (Flaskerud and Strehlow, 2008). Homelessness is often triggered by violence, trauma and adversity in childhood that makes the 'homeless culture' attractive in giving status and acceptance to these individuals (Ravenhill, 2008). Flaskerud and Strehlow (2008) suggest that apparent apathy and neglect of this highly marginalized, traumatized and disadvantaged population might be due to our belief in individual responsibility, free will and self-determination. As the author rightly points out, the dearth of CBT studies in this area is troubling. There is evidence to suggest that CBT needs to be culturally adapted for the Mexicans (Organista and Muñoz, 1996; Shea et al., 2016) and we therefore envisage that adaptation took place at three levels: (1) for broader Mexican culture, (2) for the homeless, and (3) for the youth. We encourage the authors to share in-depth details of adaptations for application across countries and cultures.

\section{(e) Religion and CBT}

\section{Cultural adaptations of CBT for the British Jewish Orthodox community (Kada, 2019)}

Raphael Kada (Kada, 2019) describes his experience of providing CBT for the Jewish community. Kada suggests adaptations both at the individual therapist level (to make therapy acceptable) and at the service level (to improve access and engagement). They discuss the barriers in access to CBT, such as stigma and racism (mistrust of services and service providers), therapist's level of awareness (gender, religion and rituals), the religious beliefs (depression occurring only in those who are not genuinely religious) as well as the level of religiosity (Orthodox, Liberal, Conservative and Reform, non-affiliated or secular Jews). Finally, Kada endorses community-based services (Beck and Naz, 2019), the use of neutral places for therapy, and the importance of social media and online platforms in this context. 
This paper offers a wealth of information and insights, and highlights the need for incorporating religious and spiritual factors in formulation and treatment (Josephson, 2004; Miller, 2004). Some of this information might even be useful when working with service users from other Abrahamic religions. These findings are consistent with North American literature on culturally adapting CBT (Rosen et al., 2014; Shabtai et al., 2016) and to improve access to mental health services for Jews (McEvoy et al., 2017). The belief that not being a pious person is associated with depression or anxiety is also common among other religious groups (Mir et al., 2019; Naeem et al., 2015a). Similarly, racism as a barrier to access to help and as a cause for the emotional and mental health problem has been previously reported (Rathod et al., 2010; Ward and Brown, 2015). There is also evidence to suggest that using online platforms for delivering CBT might address cultural barriers (Alavi et al., 2016). This work encourages us to discuss the client's religious and cultural beliefs and to engage the client as experts not only in their problems but also in their culture and religion.

\section{Delivering a culturally adapted therapy for Muslim service users with depression (Mir et al., 2019)}

Ghazala Mir and co-workers have culturally adapted behavioural activation (BA) for Muslim service users in England. They describe the critical elements of the adapted intervention using case summaries. They describe their experience of successfully training therapists in delivering culturally adapted BA, which supports Muslim service users who choose to use 'positive religious coping' as a resource for health. In addition to adapting BA, they have developed a self-help booklet. Therapy was adapted using qualitative methods while maintaining the theoretical underpinning of BA and was found to be feasible and acceptable (Mir et al., 2015). The intervention is also available online (https://medicinehealth.leeds.ac.uk/downloads/ download/131/results_and_resources_for_addressing_depression_in_muslim_communities).

As far as I know, this is the only evidence-based intervention that was adapted for a religious group in England and is being implemented in at least some parts of the service. A systematic review of interventions for treating depression in Muslim patients reported that many studies do not distinguish between beliefs and values that are religious and those that are cultural, and that most of the evidence was methodologically weak or included assertions made without qualification (Walpole et al., 2013). This implies that interventions adapted for religious groups should take into consideration the cultural factors as well. Ghazala Mir and colleagues have very thoughtfully incorporated religious concepts in this intervention, such as self-compassion, hope and taking responsibility for one's actions, and have addressed misconceptions around religious teachings. Most importantly, they address the cultural issues too. Culture can influence religions, such as a blue-eyed Jesus in Europe and an Indian-looking Jesus in South Asia (Trendpost, 2015). Islam is not an exception, and there are variations in the application of Islamic beliefs in different cultures and traditions (The Economist, 2013). Finally, I agree with the authors that this intervention should be used across the board. Evidence from fully powered trials will help towards implementation not just in England but in Muslim countries too.

\section{(f) Service delivery, the practice of therapy and training}

The need for service change and community outreach work to support trans-cultural cognitive behaviour therapy with Black and Minority Ethnic communities (Beck and Naz, 2019)

In this thought-provoking article, the authors argue that attempts to culturally adapt interventions for Black and Minority ethnic (BME) service users will not have the desired impact if sufficient measures are not in place to improve access to psychological services. They describe some examples from their work to show how the services can better understand the needs of minority populations. The over-arching theme of the paper is the engagement of the BME 
community in a collaborative manner while addressing stigma and with an emphasis on services being flexible in order to engage BME communities.

This paper highlights the need to improve the BME community's access to CBT. These ideas have significant implications for equity in terms of service provision. The authors point out that the NICE guidelines do not look at the suitability of cultural adaptations of CBT or how services could be best organized to meet the needs of BME populations. They rightly point out that adaptation work does not suggest changes in mental health care systems. While literature reports perceived barriers to accessing mental health services among BME communities (Memon et al., 2016), not many models of improving access to psychological services for the BME group exist. Memon et al. (2016) describe factors affecting the relationship between service users and healthcare providers, e.g. poor communication, inadequate recognition or response to mental health needs, cultural naivety, insensitivity and discrimination as well as lack of awareness of different services among service users and providers. I agree that community centres might be a suitable alternative to deal with stigma. This will require establishing trust and partnership with the community. There is a need for further research on a model developed by these authors, which has been tried elsewhere (Baillie et al., 2014; CFHI, 2018). In the end, political will, lobbying, public awareness and public demand play an important role in changes in service delivery and improving access to care.

\section{An evaluation of the transition from the BAME community mental health worker to IAPT low- intensity psychological wellbeing practitioner (Hakim et al., 2019)}

Hakim et al. (2019) explored the experience of four IAPT low-intensity Psychological Wellbeing Practitioners (PWP) who had previously worked as BME Community Mental Health Workers (CMHW). The participants reported that low-intensity CBT (LiCBT) was useful, but only when cultural adaptations were made. They identified six significant themes: training experience in two different roles, the broader context of both services and their accessibility to the BME service users, differences encountered, adapting therapy for BME service users and therapists' language and cultural expertise not being valued. Authors suggest that there can be significant benefits for services to provide IAPT training to people already providing culturally specific services.

This small-scale study offers in-depth insights based on the experience of front-line workers. They describe their efforts in adapting therapy for their service users on an individual level, barriers to access to IAPT services and lack of training for therapists from majority ethnic backgrounds. It makes common sense that experienced health professionals regardless of their background can offer extra advantages to their service users if they transition to the IAPT. Other authors have suggested the idea that neutral places in the community might improve access to services and engagement with the BME communities (Beck and Naz, 2019; Kada, 2019). Similarly, their suggestion in adapting CBT is also in line with other papers in this issue. The idea of therapist matching has been a topic of debate; however, research in this area has reported mixed results (Flaskerud, 1990; Lambert, 2016). Therefore, practical measures to improve access and providing training in culturally adapted therapy might be the most practical way forward. Future research in this area should explore stakeholders' views on improving access to IAPT services for BME communities.

Addressing issues of race, ethnicity and culture in CBT to support therapists and service managers to deliver culturally competent therapy and reduce inequalities in mental health provision for BAME service users (Naz et al., 2019)

This paper describes the authors' experience of delivering training in culturally sensitive CBT, thoughtful commentary on race relations in England, and improving access to CBT for BME clients. The authors provide their perspectives on the terms race, culture and ethnicity and share their understanding of these terms for CBT therapists. They provide best practice guidelines for 
BME and White therapists, as well as service managers to enable them to work more effectively with service users from different ethnic and cultural backgrounds, for example to consider the current socio-political context. They emphasize the need to provide training and supervision to deliver culturally competent care to BME service users and encourage self-reflection among therapists. They highlight the need for commitment and investment, by all stakeholders, such as therapists, supervisors, clinical leads, service managers, Clinical Commissioning Groups (CCGs) and NHS England. Finally, the authors argue that more resources are required to understand and address the barriers to accessing mental health services for BME service users.

This paper addresses issues above and beyond cultural adaptation of interventions and provides insights into the racial, political and health systems related issues, and most importantly the conflicts these issues can cause among therapists. This article emphasizes the role of mental health services and accreditation bodies. However, this will require a two-pronged approach: improving race relations at a national level and working closely with the accreditation bodies and service providers through canvassing, and emphasizing the role social factors play in the management of emotional and mental health problems. Building an evidence base through high-quality research will further strengthen their argument. Finally, cultural considerations should be an essential part of the CBT courses and training of new CBT therapists. Currently, the IASP (Improving Access to Structures Psychotherapies) CBT Training Program in Ontario, Canada, is incorporating culturally adapted CBT practices.

\section{Understanding Black and Minority Ethnic service user's experience of racism as part of the assessment, formulation and treatment of mental health problems in cognitive behaviour therapy (Beck, 2019)}

Andrew Beck starts by presenting evidence that experience of racism can be a cumulative risk factor for developing mental health problems. Therapists often do not discuss service users' experiences of racism. The author encourages therapists working with BME service users to develop skills to discuss their race, ethnicity, religion and experiences of racism with their service users. This information can then be used to enhance therapeutic alliance and inform formulation and treatment. They offer practical advice on discussing these issues.

Beck discusses issues related to a topic sensitively and compassionately that many might find challenging. Most importantly, he provides practical guidance on how to do this: the appropriate time to make such enquiries, co-developing a genogram, carefully phrasing questions and use of information gathered to guide treatment. While some therapists might be less interested in these topics, others might not explore these areas due to their anxieties around race relations. There are wider cultural variations in self-disclosure. There is at least some evidence that people from some non-Western culture are less likely to self disclose (Chen, 1995; Yoo, 2012). I encourage the author to develop this work in the form of a training workshop. This area merits further research.

\section{Cognitive behavioural therapy training in Tanzania: a qualitative study of clinicians' experiences (Stone and Arroll, 2019)}

Stone and Arroll report a qualitative study to explore the experiences of therapists trained in CBT in Tanzania. Seven participants from Tanzania's only psychiatric hospital who had completed CBT training were interviewed. The results of the qualitative analysis found five superordinate themes: the medical model, novelty, practicalities, process and therapist effects. They discuss two themes ('therapist effects' and 'process') in detail, as they believe these to be particularly relevant to the clinical application of the therapy in this context.

Stone and Warren previously reported the development and implementation of a CBT training course for clinicians working in Tanzania (Stone and Warren, 2011). Followed by their pioneering work, more studies have been published from Tanzania (O’Donnell et al., 2014; Woods-Jaeger 
et al., 2017). The findings of Stone and Warren, in particular people in low- and middle-income countries not being aware of the existence of modern psychotherapies and professional's reliance on a medical model, are in line with published literature (Naeem et al., 2010). It is possible that people presenting with biological symptoms of depression and anxiety attend the modern health facilities, while those with predominantly psychological symptoms or those with a spiritual model of illness, attend faith or religious healers (Naeem, 2013; Naeem et al., 2015a). Tanzania, like many other low- and middle-income countries, has a long tradition of faith healers ( $\mathrm{Li}, 2011)$. There is a need to improve knowledge of evidence-based therapies through popular electronic and social media, as well as teaching and training health workers.

\section{The importance of using reflective practice when working with refugees, asylum seekers and survivors of torture within IAPT (Brooks, 2019)}

In this article, Michelle Brooks emphasizes the need for the reflective practice, self-practice and critical incident analysis model when working with service users with complex needs, such as refugees, asylum seekers and survivors of torture attending the IAPT (Improving Access to Psychological Therapies) programme. Brooks identifies some of the challenges that refugees, asylum seekers and survivors of torture may present with. The critical incident analysis model consists of a five-stage process: (1) account of the incident, (2) initial responses to the incident, (3) issues and dilemmas highlighted by this incident, (4) learning and (5) outcomes. Brooks uses a case example to further elaborate the model and emphasize the need for further research in this area.

Therapists working with traumatized individuals are at increased risk of burnout, compassion fatigue and vicarious trauma (Iqbal, 2015). When working with refugees, these therapists have to face multiple barriers, such as language, religion and culture. This can indeed increase the risks mentioned above. Self-practice, self-reflection (Chigwedere et al., 2019) and the critical incident analysis model can be useful tools for these therapists. A survey of compassion satisfaction, burnout and secondary traumatic stress of British therapists working with traumatized individuals reported that a higher risk of secondary traumatic stress was predicted in therapists engaging in more individual supervision and self-care activities and those with a personal trauma history (Sodeke-Gregson et al., 2013). Another survey from Canada reported time spent with trauma victims to be the strongest predictor of the traumatic stress. There was no association between time devoted to coping strategies and traumatic stress scores (Bober and Regehr, 2006). I agree with the authors about the need for more research in this area.

\section{Culture and therapist self-disclosure (Phiri et al., 2019)}

Peter Phiri and colleagues present findings from a sub-analysis of a qualitative study to culturally adapt CBT for psychosis for people of Afro-Caribbean and South Asian background (Rathod et al., 2010). Their original study consisted of individual in-depth face-to-face interviews with patients with psychosis $(n=15)$ and focused groups with lay members $(n=52)$, CBT therapists $(n=22)$ and mental health practitioners $(n=25)$. This paper describes one of the themes from that study in greater detail, i.e. client initiated therapist self-disclosure (TSD). The authors used thematic analysis to further elaborate on critical elements of this theme and how this could impact on (a) therapists' reaction towards TSD, (b) the therapeutic alliance, and ultimately (c) the outcomes of therapy. They suggest that some BME client groups might test their therapist through initiating TSD. It is not the content of the TSD they are testing per se, but how the therapist responds. In addition to providing some guidance for therapists, Phiri et al. discuss the pros and cons of TSD. They propose further investigation in this area. 
As far as I know, this is the first paper to address TSD in a cultural context. Phiri and colleagues used a systematic approach to culturally adapt CBTp (Rathod et al., 2010) in England. This Ca-CBTp was found to be feasible and acceptable as well as effective in a pilot RCT (Rathod et al., 2013). Based on this initial research and their clinical experience, and in order to further improve strategies to improve therapeutic alliance and engagement, they discuss TSD in this article. However, we should also keep in mind that service users from different cultural backgrounds vary in their tendency to self-disclosure (Chen, 1995; Yoo, 2012). Their experience of racism, perceived biases and discrimination mean that TSD can play a vital role in building trust and improving engagement (Beck and Naz, 2019). Therefore, sensitive use of TSD considered to be a useful tool (Goldfried et al., 2003) becomes even more critical when working with BME communities.

\section{Conclusions}

Human societies are evolving at a fast pace. Globalization is bringing people together, and increasing their knowledge and awareness of the latest technologies in healthcare. Globalization also means rapid mobilization of people across national boundaries. We are becoming more mindful of the need to equal rights of all members of society, and to all societies and cultures and sub-cultures. Therefore, for CBT to stay in the system, it has to evolve, to adapt and even integrate other systems of therapies, in order to address the demands of people with a variety of needs. The original Beckian CBT model has been adapted over the years to help service users with anxiety, PTSD, OCD and psychosis. Third wave therapies are good examples of integration of CBT with another model of therapy. Adaptation of CBT for service users from a variety of cultures and sub-cultures can be seen as an extension of this process. This special issue publishes papers on both adaptation and integration of therapies to fulfil the needs of groups with complex needs and from different cultures and sub-cultures.

It is heartening to see the breadth and width of topics covered in this special issue. The authors have used a variety of approaches to describe their experiences of working with people from diverse backgrounds. Future research must focus on systematically adapting CBT that can be tested through fully powered trials and evaluated for cost-effectiveness. There is also a need to test the culture-free aspects of CBT. Most importantly, a focus on the implementation of adapted CBT, service development and improving access to adapted CBT is required, which can only happen with building the evidence base and advocacy for the right to evidence-based care.

Conflicts of interest. None.

Ethics statement. This review did not require ethics committee approval.

\section{References}

Alatiq, Y, \& Alrshoud, H (2018). Family-based cognitive behavioural therapy for obsessive-compulsive disorder with family accommodation: case report from Saudi Arabia. The Cognitive Behaviour Therapist, 11. https://doi.org/10.1017/ S1754470X1800017X

Alavi, N, Hirji, A, Sutton, C, \& Naeem, F (2016). Online CBT is effective in overcoming cultural and language barriers in patients with depression. Journal of Psychiatric Practice, 22, 2-8. https://doi.org/10.1097/PRA.0000000000000119

Altweck, L, Marshall, TC, Ferenczi, N, \& Lefringhausen, K (2015). Mental health literacy: a cross-cultural approach to knowledge and beliefs about depression, schizophrenia and generalized anxiety disorder. Frontiers in Psychology, 6. https://doi.org/10.3389/fpsyg.2015.01272

Baillie, J, Harrop, E, Hopewell-Kelly, N, Stephens, K, Byrne, A, \& Nelson, A (2014). Engaging minority ethnic communities to improve access to palliative care: barriers and strategies. BMJ Supportive \& Palliative Care, 4, 114-114. https://doi.org/10. 1136/bmjspcare-2014-000653.28 
Beck, A (2016). Transcultural Cognitive Behaviour Therapy for Anxiety and Depression: A Practical Guide, 1st edition (paperback), Routledge [text]. Retrieved 6 May 2019 from Routledge.com website: https://www.routledge.com/ Transcultural-Cognitive-Behaviour-Therapy-for-Anxiety-and-Depression-A/Beck/p/book/9781138890480

Beck, A (2019). Understanding black and minority ethnic service user's experience of racism as part of the assessment, formulation and treatment of mental health problems in cognitive behaviour therapy. The Cognitive Behaviour Therapist, 12. https://doi.org/10.1017/S1754470X18000223

Beck, A, \& Naz, S (2019). The need for service change and community outreach work to support trans-cultural cognitive behaviour therapy with black and minority ethnic communities. The Cognitive Behaviour Therapist, 12. https://doi.org/10. 1017/S1754470X18000016

Berry, K, Day, C, Mulligan, LD, Seed, T, Degnan, A, \& Edge, D (2018). Culturally adapted Family Intervention (CaFI): case examples from therapists' perspectives. The Cognitive Behaviour Therapist, 11. https://doi.org/10.1017/ S1754470X18000156

Bhugra, D (2006). Severe mental illness across cultures. Acta Psychiatrica Scandinavica, Supplementum (429), 17-23. https:// doi.org/10.1111/j.1600-0447.2005.00712.x

Bhugra, D, \& Bhui, K (1998). Psychotherapy for ethnic minorities: issues, context and practice. British Journal of Psychotherapy, 14, 310-326. https://doi.org/10.1111/j.1752-0118.1998.tb00385.x

Bober, T, \& Regehr, C (2006). Strategies for reducing secondary or vicarious trauma: do they work? Brief Treatment and Crisis Intervention, 6, 1. https://doi.org/10.1093/brief-treatment/mhj001

Bolton, P, Lee, C, Haroz, EE, Murray, L, Dorsey, S, Robinson, C, ... \& Bass, J (2014). A transdiagnostic community-based mental health treatment for comorbid disorders: development and outcomes of a randomized controlled trial among Burmese refugees in Thailand. PLOS Medicine, 11, e1001757. https://doi.org/10.1371/journal. pmed. 1001757

Bonilla-Escobar, FJ, Fandiño-Losada, A, Martínez-Buitrago, DM, Santaella-Tenorio, J, Tobón-García, D, MuñozMorales, EJ, ... \& Bolton, P (2018). A randomized controlled trial of a transdiagnostic cognitive-behavioral intervention for Afro-descendants' survivors of systemic violence in Colombia. PLOS One, 13, e0208483. https://doi. org/10.1371/journal.pone.0208483

Bowen, DJ, \& Boehmer, U (2007). The lack of cancer surveillance data on sexual minorities and strategies for change. Cancer Causes \& Control: CCC, 18, 343-349. https://doi.org/10.1007/s10552-007-0115-1

Brooks, M (2019). The importance of using reflective practice when working with refugees, asylum seekers and survivors of torture within IAPT. The Cognitive Behaviour Therapist, 12. https://doi.org/10.1017/S1754470X19000023

Castaños-Cervantes, S (2019). Brief CBT group therapy for Mexican homeless girls. The Cognitive Behaviour Therapist, 12. https://doi.org/10.1017/S1754470X18000272

CFHI (2018, 15 September). CFHI - Implementing a 'Navigator' Model in Emerging Mental Illness. Retrieved 15 September 2018 from: www.cfhi-fcass.ca website: https://www.cfhi-fcass.ca/WhatWeDo/extra/improvement-projects/Cohorts/ 2010EXTRACompetitionResults/project6

Chen, G-M (1995). Differences in self-disclosure patterns among Americans versus Chinese: a comparative study. Journal of Cross-Cultural Psychology, 26, 84-91. https://doi.org/10.1177/0022022195261006

Cheng, P-H, \& Merrick, E (2017). Cultural adaptation of dialectical behavior therapy for a Chinese international student with eating disorder and depression. Clinical Case Studies, 16, 42-57. https://doi.org/10.1177/1534650116668269

Chessell, ZJ, Brady, F, Akbar, S, Stevens, A, \& Young, K (2019). A protocol for managing dissociative symptoms in refugee populations. The Cognitive Behaviour Therapist, 12. https://doi.org/10.1017/S1754470X19000114

Chigwedere, C, Thwaites, R, Fitzmaurice, B, \& Donohoe, G (2019). Self-practice/self-reflection as an alternative to personal training-therapy in cognitive behavioural therapy training: a qualitative analysis. Clinical Psychology \& Psychotherapy, 26, 74-83. https://doi.org/10.1002/cpp.2331

Cinnirella, M, \& Loewenthal, KM (1999). Religious and ethnic group influences on beliefs about mental illness: a qualitative interview study. British Journal of Medical Psychology, 72, 505-524. https://doi.org/10.1348/000711299160202

Cultural Atlas (2019). Chinese Culture- Greetings. Retrieved 21 May 2019 from Cultural Atlas website: https://culturalatlas. sbs.com.au/chinese-culture/greetings

Edge, D, Degnan, A, Cotterill, S, Berry, K, Baker, J, Drake, R, \& Abel, K (2018a). Culturally adapted Family Intervention (CaFI) for African-Caribbean people diagnosed with schizophrenia and their families: a mixed-methods feasibility study of development, implementation and acceptability. Retrieved from: http://www.ncbi.nlm.nih.gov/ books/NBK525363/

Edge, D, Degnan, A, Cotterill, S, Berry, K, Baker, J, Drake, R, \& Abel, K (2018b). Developing CaFI: a consensus conference. Retrieved from: https:/www.ncbi.nlm.nih.gov/books/NBK525366/

Ellis, BJ, Jackson, JJ, \& Boyce, WT (2006). The stress response systems: universality and adaptive individual differences. Developmental Review, 26, 175-212. https://doi.org/10.1016/j.dr.2006.02.004

El-Rouayheb, K (2005). Before Homosexuality in the Arab-Islamic World, 1500-1800. Retrieved from: https://www.press. uchicago.edu/ucp/books/book/chicago/B/bo3613572.html 
Fearon, P, Kirkbride, JB, Morgan, C, Dazzan, P, Morgan, K, Lloyd, T, ... \& Murray, RM (2006). Incidence of schizophrenia and other psychoses in ethnic minority groups: results from the MRC AESOP Study. Psychological Medicine, 36, 1541-1550. https://doi.org/10.1017/S0033291706008774

Flaskerud, JH (1990). Matching client and therapist ethnicity, language, and gender: a review of research. Issues in Mental Health Nursing, 11, 321-336. https://doi.org/10.3109/01612849009006520

Flaskerud, JH, \& Strehlow, AJ (2008). A culture of homelessness? Issues in Mental Health Nursing, 29, 1151-1154. https://doi. org/10.1080/01612840802319688

Fuchs, C, Lee, JK, Roemer, L, \& Orsillo, SM (2013). Using mindfulness- and acceptance-based treatments with clients from nondominant cultural and/or marginalized backgrounds: clinical considerations, meta-analysis findings, and introduction to the special series. Cognitive and Behavioral Practice, 20, 1-12. https://doi.org/10.1016/j.cbpra.2011. 12.004

Fung, K (2015). Acceptance and commitment therapy: Western adoption of Buddhist tenets? Transcultural Psychiatry, 52, 561-576. https://doi.org/10.1177/1363461514537544

Goldfried, MR, Burckell, LA, \& Eubanks-Carter, C (2003). Therapist self-disclosure in cognitive-behavior therapy. Journal of Clinical Psychology, 59, 555-568. https://doi.org/10.1002/jclp.10159

Gouda, M, \& Potrafke, N (2016). Gender equality in Muslim-majority countries. Economic Systems, 40, 683-698. https://doi. org/10.1016/j.ecosys.2016.04.002

Gureje, O, Nortje, G, Makanjuola, V, Oladeji, B, Seedat, S, \& Jenkins, R (2015). The role of global traditional and complementary systems of medicine in treating mental health problems. The Lancet. Psychiatry, 2, 168-177. https:// doi.org/10.1016/S2215-0366(15)00013-9

Hagmayer, Y, \& Engelmann, N (2014). Causal beliefs about depression in different cultural groups - what do cognitive psychological theories of causal learning and reasoning predict? Frontiers in Psychology, 5. https://doi.org/10.3389/ fpsyg.2014.01303

Hakim, N, Thompson, AR, \& Coleman-Oluwabusola, G (2019). An evaluation of the transition from BAME community mental health worker to IAPT low intensity psychological wellbeing practitioner. The Cognitive Behaviour Therapist, 12. https://doi.org/10.1017/S1754470X18000296

Hall, L (2011). The importance of understanding military culture. Social Work in Health Care, 50, 4-18. https://doi.org/10. 1080/00981389.2010.513914

Hawton, K, Witt, KG, Taylor Salisbury, TL, Arensman, E, Gunnell, D, Hazell, P, ... \& van Heeringen, K (2016). Psychosocial interventions for self-harm in adults. The Cochrane Database of Systematic Reviews, (5), CD012189. https://doi.org/10.1002/14651858.CD012189

Hays, PA, \& Iwamasa, GY (eds). (2006). Culturally Responsive Cognitive-Behavioral Therapy: Assessment, Practice, and Supervision. Washington, DC, USA: American Psychological Association.

Herek, GM, Gillis, JR, \& Cogan, JC (2009). Internalized stigma among sexual minority adults: insights from a social psychological perspective. Journal of Counseling Psychology, 56, 32-43. https://doi.org/10.1037/a0014672

Hofmann, SG, Asnaani, A, \& Hinton, DE (2010). Cultural aspects in social anxiety and social anxiety disorder. Depression and Anxiety, 27, 1117-1127. https://doi.org/10.1002/da.20759

Hoge, CW, Castro, CA, Messer, SC, McGurk, D, Cotting, DI, \& Koffman, RL (2004). Combat duty in Iraq and Afghanistan, mental health problems, and barriers to care. New England Journal of Medicine, 351, 13-22. https://doi.org/10.1056/ NEJMoa040603

Hwang, W-C, Myers, HF, Chiu, E, Mak, E, Butner, JE, Fujimoto, K, . . \& Miranda, J (2015). Culturally adapted cognitivebehavioral therapy for Chinese Americans with depression: a randomized controlled trial. Psychiatric Services (Washington, DC), 66, 1035-1042. https://doi.org/10.1176/appi.ps.201400358

Illing, S (2019, 29 March). Mindfulness meditation in America has a capitalism problem. Retrieved 28 April 2019 from Vox website: https://www.vox.com/science-and-health/2019/3/29/18264703/mindfulness-meditation-buddhism-david-forbes

Iqbal, A (2015). The ethical considerations of counselling psychologists working with trauma: is there a risk of vicarious traumatisation? Counselling Psychology Review, 30, 44-51.

Ismail, H, Wright, J, Rhodes, P, \& Small, N (2005). Religious beliefs about causes and treatment of epilepsy. British Journal of General Practice, 55, 26-31.

Jankowska, M (2019). Cultural modifications of cognitive behavioural treatment of social anxiety among culturally diverse clients: a systematic literature review. The Cognitive Behaviour Therapist, 12. https://doi.org/10.1017/ S1754470X18000211

Joseph, S, \& DiDuca, D (2007). The Dimensions of Religiosity Scale: 20-item self-report measure of religious preoccupation, guidance, conviction, and emotional involvement. Mental Health, Religion \& Culture, 10, 603-608. https://doi.org/10.1080/ 13674670601050295

Josephson, AM (2004). Formulation and treatment: integrating religion and spirituality in clinical practice. Child and Adolescent Psychiatric Clinics of North America, 13, 71-84.

Kada, R. (2019). Cultural adaptations of CBT for the British Jewish Orthodox community. The Cognitive Behaviour Therapist, 12. https://doi.org/10.1017/S1754470X18000120 
Kayrouz, R, Dear, BF, Kayrouz, B, Karin, E, Gandy, M, \& Titov, N (2018). Meta-analysis of the efficacy and acceptability of cognitive-behavioural therapy for Arab adult populations experiencing anxiety, depression or post-traumatic stress disorder. Cognitive Behaviour Therapy, 47, 412-430. https://doi.org/10.1080/16506073.2018.1445124

King, D, \& Said, G (2019). Working with unaccompanied asylum-seeking young people: cultural considerations and acceptability of a cognitive behavioural group approach. The Cognitive Behaviour Therapist, 12. https://doi.org/10. 1017/S1754470X18000260

Kirmayer, LJ (2015). Mindfulness in cultural context. Retrieved 28 April 2019 from: https://journals.sagepub.com/doi/full/10. 1177/1363461515598949

Kolonia, K, Tsartsara, E, \& Giakoumaki, O (2019). Schema Therapy and the use of Politeness Plural in Greek-speaking populations: a need for cultural adaptation or a quest for early maladaptive schemas/modes? The Cognitive Behaviour Therapist, 12. https://doi.org/10.1017/S1754470X18000302

Lambert, MJ (2016). Does client-therapist gender matching influence therapy course or outcome in psychotherapy? Evidence Based Medicine and Practice, 2, 1-8. https://doi.org/10.4172/2471-9919.1000108

Langroudi, KF, \& Skinta, MD (2019). Working with gender and sexual minorities in the context of Islamic culture: a queer Muslim behavioural approach. The Cognitive Behaviour Therapist, 12. https://doi.org/10.1017/ S1754470X19000096

Li, V (2011). Faith: friend or foe? The rise of faith healing in Tanzania and its impact on community understanding of HIV. The Journal of Global Health. Retrieved from: www.ghjournal.org/faith-friend-or-foe/

Li, W, Zhang, L, Luo, X, Liu, B, Liu, Z, Lin, F, . . \& Naeem, F (2017). A qualitative study to explore views of patients', carers' and mental health professionals' to inform cultural adaptation of CBT for psychosis (CBTp) in China. BMC Psychiatry, 17. https://doi.org/10.1186/s12888-017-1290-6

Linehan, MM, Armstrong, HE, Suarez, A, Allmon, D, \& Heard, HL (1991). Cognitive-behavioral treatment of chronically parasuicidal borderline patients. Archives of General Psychiatry, 48, 1060-1064.

McEvoy, P, Williamson, T, Kada, R, Frazer, D, Dhliwayo, C, \& Gask, L (2017). Improving access to mental health care in an Orthodox Jewish community: a critical reflection upon the accommodation of otherness. BMC Health Services Research, 17, 557. https://doi.org/10.1186/s12913-017-2509-4

Memon, A, Taylor, K, Mohebati, LM, Sundin, J, Cooper, M, Scanlon, T, \& Visser, R de (2016). Perceived barriers to accessing mental health services among black and minority ethnic (BME) communities: a qualitative study in Southeast England. BMJ Open, 6, e012337. https://doi.org/10.1136/bmjopen-2016-012337

Méndez-Bustos, P, Calati, R, Rubio-Ramírez, F, Olié, E, Courtet, P, \& Lopez-Castroman, J (2019). Effectiveness of psychotherapy on suicidal risk: a systematic review of observational studies. Frontiers in Psychology, 10. https://doi.org/ 10.3389/fpsyg.2019.00277

Mercado, A, \& Hinojosa, Y (2017). Culturally adapted dialectical behavior therapy in an underserved community mental health setting: a latina adult case study. Practice Innovations, 2, 80-93. https://doi.org/10.1037/pri0000045

Meyer, IH (2003). Prejudice, social stress, and mental health in lesbian, gay, and bisexual populations: conceptual issues and research evidence. Psychological Bulletin, 129, 674-697. https://doi.org/10.1037/0033-2909.129.5.674

Miller, L (Laurence) (2010). Psychotherapy with military personnel: lessons learned, challenges ahead. International Journal of Emergency Mental Health, 12, 179-192.

Miller, L (Lisa) (2004). A spiritual formulation of interpersonal psychotherapy for depression in pregnant girls. In Casebook for a Spiritual Strategy in Counseling and Psychotherapy (pp. 75-86). https://doi.org/10.1037/10652-004

Mir, G, Ghani, R, Meer, S, \& Hussain, G (2019). Delivering a culturally adapted therapy for Muslim clients with depression. The Cognitive Behaviour Therapist, 12. https://doi.org/10.1017/S1754470X19000059

Mir, G, Meer, S, Cottrell, D, McMillan, D, House, A, \& Kanter, JW (2015). Adapted behavioural activation for the treatment of depression in Muslims. Journal of Affective Disorders, 180, 190-199. https://doi.org/10.1016/j.jad. 2015.03.060

Morgan, C, Dazzan, P, Morgan, K, Jones, P, Harrison, G, Leff, J, . . \& Fearon, P (2006). First episode psychosis and ethnicity: initial findings from the AESOP study. World Psychiatry, 5, 40-46.

Murray, LK, Haroz, EE, Pullmann, MD, Dorsey, S, Kane, J, Augustinavicius, J, . . \& Bolton, P (2019). Under the hood: lay counsellor element use in a modular multi-problem transdiagnostic intervention in lower resource countries. The Cognitive Behaviour Therapist, 12. https://doi.org/10.1017/S1754470X18000144

Naeem, F (2013). Culturally Adapted CBT (CaCBT) for Depression, Therapy Manual for Use with South Asian Muslims [Kindle edition].

Naeem, F, Gobbi, M, Ayub, M, Kingdon, D, et al. (2010). Psychologists experience of cognitive behaviour therapy in a developing country: a qualitative study from Pakistan. International Journal of Mental Health Systems, 4.

Naeem, F, Rathod, S, Khan, N, \& Ayub, M (2016a). Challenges in developing feasible and cost effective culturally adapted therapy that can be used by the local health systems in LAMICs. The British Journal of Psychiatry, 208.

Naeem, F, Habib, N, Gul, M, Khalid, M, Saeed, S, Farooq, S, .. . \& Kingdon, D (2014). A qualitative study to explore patients', carers' and health professionals' views to culturally adapt CBT for psychosis (CBTp) in Pakistan. Behavioural and Cognitive Psychotherapy, 1-13. https://doi.org/10.1017/S1352465814000332 
Naeem, F, Phiri, P, Munshi, T, Rathod, S, Ayub, M, Gobbi, M, \& Kingdon, D (2015a). Using cognitive behaviour therapy with South Asian Muslims: findings from the culturally sensitive CBT project. International Review of Psychiatry, 27, 233-246. https://doi.org/10.3109/09540261.2015.1067598

Naeem, F, Phiri, P, Nasar, A, Munshi, T, Ayub, M, \& Rathod, S (2016b). An evidence-based framework for cultural adaptation of cognitive behaviour therapy: process, methodology and foci of adaptation. World Cultural Psychiatry Research Review, 11, 67-70.

Naeem, F, Phiri, P, Rathod, S, \& Ayub, M (2019). Cultural adaptation of cognitive-behavioural therapy. BJPsych Advances, 1-9. https://doi.org/10.1192/bja.2019.15

Naeem, F, Saeed, S, Irfan, M, Kiran, T, Mehmood, N, Gul, M, . . \& Kingdon, D (2015b). Brief culturally adapted CBT for psychosis (CaCBTp): a randomized controlled trial from a low income country. Schizophrenia Research. https://doi.org/10. 1016/j.schres.2015.02.015

Naz, S, Gregory, R, \& Bahu, M (2019). Addressing issues of race, ethnicity and culture in CBT to support therapists and service managers to deliver culturally competent therapy and reduce inequalities in mental health provision for BAME service users. The Cognitive Behaviour Therapist, 12. https://doi.org/10.1017/S1754470X19000060

NICE (2014). Psychosis and schizophrenia in adults: prevention and management. Guidance and guidelines. Retrieved 7 February 2016 from: http://www.nice.org.uk/guidance/cg178

O'Donnell, K, Dorsey, S, Gong, W, Ostermann, J, Whetten, R, Cohen, JA, . . \& Whetten, K (2014). Treating unresolved grief and posttraumatic stress symptoms in orphaned children in Tanzania: group-based trauma-focused cognitive behavioral therapy. Journal of Traumatic Stress, 27, 664-671. https://doi.org/10.1002/jts.21970

Organista, KC, \& Muñoz, RF (1996). Cognitive behavioral therapy with Latinos. Cognitive and Behavioral Practice, 3, 255270. https://doi.org/10.1016/S1077-7229(96)80017-4

Panos, PT, Jackson, JW, Hasan, O, \& Panos, A (2014). Meta-analysis and systematic review assessing the efficacy of dialectical behavior therapy (DBT). Research on Social Work Practice, 24, 213-223. https://doi.org/10.1177/ 1049731513503047

Patel, V, Weiss, HA, Chowdhary, N, Naik, S, Pednekar, S, Chatterjee, S, . . \& Kirkwood, B (2010). The effectiveness of a lay health worker led intervention for depressive and anxiety disorders in primary care: the MANAS cluster randomized trial in Goa, India. Lancet, 376, 2086-2095. https://doi.org/10.1016/S0140-6736(10)61508-5

Perry, A, Gardener, C, Oliver, JE, Taş, Ç, \& Özenç, C (2019). Exploring the cultural flexibility of the ACT model as an effective therapeutic group intervention for Turkish speaking communities in East London. The Cognitive Behaviour Therapist, 12. https://doi.org/10.1017/S1754470X18000041

Pharoah, F, Mari, J, Rathbone, J, \& Wong, W (2010). Family intervention for schizophrenia. The Cochrane Database of Systematic Reviews, (12), CD000088. https://doi.org/10.1002/14651858.CD000088.pub2

Phiri, P, Rathod, S, Gobbi, M, Carr, H, \& Kingdon, D (2019). Culture and therapist self-disclosure. The Cognitive Behaviour Therapist, 12. https://doi.org/10.1017/S1754470X19000102

Rahman, A, Hamdani, SU, Awan, NR, Bryant, RA, Dawson, KS, Khan, MF, .. \& Ommeren, M van (2016). Effect of a multicomponent behavioral intervention in adults impaired by psychological distress in a conflict-affected area of Pakistan: a randomized clinical trial. JAMA, 316, 2609-2617. https://doi.org/10.1001/jama.2016.17165

Ramaiya, MK, Fiorillo, D, Regmi, U, Robins, CJ, \& Kohrt, BA (2017). A cultural adaptation of dialectical behavior therapy in Nepal. Cognitive and Behavioral Practice, 24, 428-444. https://doi.org/10.1016/j.cbpra.2016.12.005

Rathod, S, Kingdon, D, Phiri, P, \& Gobbi, M (2010). Developing culturally sensitive cognitive behaviour therapy for psychosis for ethnic minority patients by exploration and incorporation of service users' and health professionals' views and opinions. Behavioural and Cognitive Psychotherapy, 38, 511-533. https://doi.org/10.1017/ S1352465810000378

Rathod, S, Phiri, P, Harris, S, Underwood, C, Thagadur, M, Padmanabi, U, \& Kingdon, D (2013). Cognitive behaviour therapy for psychosis can be adapted for minority ethnic groups: a randomised controlled trial. Schizophrenia Research, 143, 319-326. https://doi.org/10.1016/j.schres.2012.11.007

Rathod, S, Phiri, P, \& Naeem, F (2019). An evidence-based framework to culturally adapt cognitive behaviour therapy. The Cognitive Behaviour Therapist, 12. https://doi.org/10.1017/S1754470X18000247

Rathod, S, Pinninti, N, Irfan, M, Gorczynski, P, Rathod, P, Gega, L, \& Naeem, F (2017). Mental health service provision in low- and middle-income countries. Health Services Insights, 10. https://doi.org/10.1177/1178632917694350

Ravenhill, M (2008). The Culture of Homelessness (1st edition). Aldershot, UK and Burlington, VT, USA: Routledge.

Razali, SM, Khan, UA, \& Hasanah, CI (1996). Belief in supernatural causes of mental illness among Malay patients: impact on treatment. Acta Psychiatrica Scandinavica, 94, 229-233. https://doi.org/10.1111/j.1600-0447. 1996.tb09854.x

Reddy, MS, \& Vijay, MS (2017). Empirical reality of dialectical behavioral therapy in borderline personality. Indian Journal of Psychological Medicine, 39, 105-108. https://doi.org/10.4103/IJPSYM.IJPSYM_132_17

Reger, MA, Etherage, JR, Reger, GM, \& Gregory, G (2008). Civilian psychologists in an army culture: the ethical challenge of cultural competence. Military Psychology, 20, 21-35. https://doi.org/10.1080/08995600701753144 
Rosen, DD, Rebeta, JL, \& Rothschild, SZ (2014). Culturally competent adaptation of cognitive-behavioural therapy for psychosis: cases of Orthodox Jewish patients with messianic delusions. Mental Health, Religion \& Culture, 17, 703713. https://doi.org/10.1080/13674676.2014.902923

Russell, RL (1989). Language and psychotherapy. Clinical Psychology Review, 9, 505-519. https://doi.org/10.1016/02727358(89)90006-8

Sahin, NH, \& Sahin, N (1992). How dysfunctional are the dysfunctional attitudes in another culture? The British Journal of Medical Psychology, 65, 17-26.

Shabtai, DG, Pirutinsky, S, \& Rosmarin, DH (2016). Integrating Judaism into Cognitive Behavioral Therapy. In M. Ben-Avie, Y. Ives \& K. Loewenthal (eds), Applied Jewish Values in Social Sciences and Psychology (pp. 133-149). https://doi.org/10.1007/978-3-319-21933-2_7

Shea, M, Cachelin, FM, Gutierrez, G, Wang, S, \& Phimphasone, P (2016). Mexican American women's perspectives on a culturally adapted cognitive-behavioral therapy guided self-help program for binge eating. Psychological Services, 13, 31-41. https://doi.org/10.1037/ser0000055

Skerven, K, Whicker, DR, \& LeMaire, KL (2019). Applying dialectical behaviour therapy to structural and internalized stigma with LGBTQ+ clients. The Cognitive Behaviour Therapist, 12. https://doi.org/10.1017/S1754470X18000235

Sodeke-Gregson, EA, Holttum, S, \& Billings, J (2013). Compassion satisfaction, burnout, and secondary traumatic stress in UK therapists who work with adult trauma clients. European Journal of Psychotraumatology, 4, 21869. https://doi.org/10. 3402/ejpt.v4i0.21869

Soeters, JL, Winslow, DJ, \& Weibull, A (2006). Military culture. In G. Caforio (ed), Handbook of the Sociology of the Military (pp. 237-254). https://doi.org/10.1007/0-387-34576-0_14

Spoont, MR, Sayer, NA, Thuras, P, Erbes, C, \& Winston, E (2003). Practical psychotherapy: adaptation of dialectical behavior therapy by a VA Medical Center. Psychiatric Services, 54, 627-629. https://doi.org/10.1176/appi.ps. 54.5.627

Statistics Canada (2014, 25 November). Mental health of the Canadian Armed Forces. Retrieved 4 May 2019 from: https:// www150.statcan.gc.ca/n1/pub/82-624-x/2014001/article/14121-eng.htm

Stevelink, SAM, Malcolm, EM, Mason, C, Jenkins, S, Sundin, J, \& Fear, NT (2015). The prevalence of mental health disorders in (ex-)military personnel with a physical impairment: a systematic review. Occupational Environmental Medicine, 72, 243-251. https://doi.org/10.1136/oemed-2014-102207

Stone, L, \& Arroll, MA (2019). Cognitive behavioural therapy training in Tanzania: a qualitative study of clinicians' experiences. The Cognitive Behaviour Therapist, 12. https://doi.org/10.1017/S1754470X19000084

Stone, L, Beck, A, Hashempour, F, \& Thwaites, R (2018). Introduction to the Special Issue on Cultural Adaptations of CBT. The Cognitive Behaviour Therapist, 11. https://doi.org/10.1017/S1754470X18000181

Stone, L, \& Warren, F (2011). Cognitive behaviour therapy training in a developing country: a pilot study in Tanzania. The Cognitive Behaviour Therapist, 4, 139-151. https://doi.org/10.1017/S1754470X11000080

Sue, S, Zane, N, Nagayama Hall, GC, \& Berger, LK (2009). The case for cultural competency in psychotherapeutic interventions. Annual Review of Psychology, 60, 525-548. https://doi.org/10.1146/annurev.psych.60.110707.163651

Suinn, RM (2003). Answering questions regarding the future directions of behavior therapy. The Behavior Therapist, 26, 282284.

Tam, PWC, Wong, DFK, Chow, KKW, Ng, FS, Ng, RMK, Cheung, MSM, .. \& Mak, ADP (2007). Qualitative analysis of dysfunctional attitudes in Chinese persons suffering from depression. Hong Kong Journal of Psychiatry, 17, 109.

The Economist (2013, 4 May). Minds unmade. Retrieved from: https://www.economist.com/international/2013/05/04/ minds-unmade

The Economist (2018, 6 June). How homosexuality became a crime in the Middle East. Retrieved from: https://www. economist.com/open-future/2018/06/06/how-homosexuality-became-a-crime-in-the-middle-east

Trendpost (2015). The Various Depictions of Jesus Around the World. Retrieved 18 May 2019 from Trends Post website: https://trendspost.com/depictions-of-jesus-around-the-world/

UNESCO (2001). UNESCO universal declaration on cultural diversity. Retrieved 30 March 2019 from: http://portal.unesco. org/en/ev.php-URL_ID=13649\&URL_DO=DO_TOPIC\&URL_SECTION=-471.html

Veltman, A, \& Chaimowitz, G (2014). Mental health care for people who identify as lesbian, gay, bisexual, transgender, and (or) queer. Canadian Journal of Psychiatry. Revue Canadienne de Psychiatrie, 59, 1-7.

Walpole, SC, McMillan, D, House, A, Cottrell, D, \& Mir, G (2013). Interventions for treating depression in Muslim patients: a systematic review. Journal of Affective Disorders, 145, 11-20. https://doi.org/10.1016/j.jad.2012.06.035

Ward, E, \& Brown, RL (2015). A culturally adapted depression intervention for African American adults experiencing depression: Oh Happy Day. The American Journal of Orthopsychiatry, 85, 11-22. https://doi.org/10.1037/ ort0000027

Weiss, WM, Murray, LK, Zangana, GAS, Mahmooth, Z, Kaysen, D, Dorsey, S, . . \& Bolton, P (2015). Community-based mental health treatments for survivors of torture and militant attacks in Southern Iraq: a randomized control trial. BMC Psychiatry, 15, 249. https://doi.org/10.1186/s12888-015-0622-7 
WHO (2015). WHO Mental Health Gap Action Programme (mhGAP). Retrieved 19 January 2016 from: http://www.who.int/ mental_health/mhgap/en/

Woods-Jaeger, BA, Kava, CM, Akiba, CF, Lucid, L, \& Dorsey, S (2017). The art and skill of delivering culturally responsive trauma-focused cognitive behavioral therapy in Tanzania and Kenya. Psychological Trauma: Theory, Research, Practice and Policy, 9, 230-238. https://doi.org/10.1037/tra0000170

Yoo, J (2012). Exploring Cross-Cultural Differences in Self-Presentation and Self-Disclosure in Social Networking Sites: A Comparison of Korean and American SNS Users (SSRN Scholarly Paper no. ID 2422292). Retrieved from Social Science Research Network website: https://papers.ssrn.com/abstract $=2422292$

Zgueb, Y, Ouali, U, Achour, R, Jomli, R, \& Nacef, F (2019). Cultural aspects of vaginismus therapy: a case series of ArabMuslim patients. The Cognitive Behaviour Therapist, 12. https://doi.org/10.1017/S1754470X18000119

Zwiebach, L, Lannert, BK, Sherrill, AM, McSweeney, LB, Sprang, K, Goodnight, JRM, . . \& Rauch, SAM (2019). Military cultural competence in the context of cognitive behavioural therapy. The Cognitive Behaviour Therapist, 12. https://doi.org/ $10.1017 /$ S1754470X18000132

Cite this article: Naeem F. Cultural adaptations of CBT: a summary and discussion of the Special Issue on Cultural Adaptation of CBT. The Cognitive Behaviour Therapist. https://doi.org/10.1017/S1754470X19000278 